\title{
Patient Effective Dose profile in CATHLAB
}

\author{
Jibon Sharma ${ }^{1}$, Jogesh Sarma ${ }^{2}$ \\ ${ }^{1}$ Department of Radiation Oncology,State Cancer Institute,Gauhati Medical College, India \\ ${ }^{2}$ Department of Pulmonary Medicine, Gauhati Medical College, India
}

\begin{abstract}
The intervention procedures are performed under fluoroscopic guidance and become increasingly common because of their obvious benefits to patients. Patient dose during cardiologic procedures is high due to lengthy procedure and the prolonged exposure time to the patient. Objective: The primary objective of the study was to evaluate the level of radiation dose received by the patients in order to estimate local diagnostic reference levels during cardiac catheterization procedures individually in terms of $\mathrm{E}$ (effective dose). Effective dose and doses to various organs estimated with the help of Monte Carlo PCXMC software.Material and Methods: A total of 123 patients were included in these studies, who were admitted to Cardiology department, and the data were collected retrospectively in a designed format during both diagnostic and therapeutic procedure.Results: The estimated patient dose rate as a whole in the Cath-Lab was found to be $96.45 \mathrm{mGy} / \mathrm{min}$ which is considered lower than the recommended DRL (dose reference level) for the continuous high mode fluoroscopy used in interventional radiology $(100 \mathrm{mGy} / \mathrm{min})$ given by IAEA. The effective dose was calculated and found respectively for CA-TFA, CA-TRA and CA-PTCA as $6.13 \mathrm{mSv}$ (range2.4-17.33), $10.97 \mathrm{mSv}$ (range 5.56-29.03) and $34.68 \mathrm{mSv}$ (range 10.6470.21). We observed strong correlation between total duration of procedure (both
\end{abstract}


fluoroscopy and cine time) with effective $\operatorname{dose}(\mathrm{R}=0.95, \mathrm{p}<0.00001)$ and a weak although statistically significant correlation between BMI (body mass index) with effective $\operatorname{dose}(\mathrm{R}=0.526, \mathrm{p}<0.00001)$ wasobserved. A significant increase of doses in TRA procedure in regard to TFA procedure was also noticed in our study.Conclusions: It is anticipated that this study is going to assist the institutions having Cath-Lab facilities of this region in encouraging the standardization of procedure, which may help increase awareness and aims to serve as guidance for Cardiologist.

Keywords: CA-TFA, CA-TRA, CA-PTCA, Effective Dose

\section{INTRODUCTION}

Over the last 20 years Interventional cardiology has expanded significantly, both in the field of diagnosis and therapy. These intervention procedures are performed under fluoroscopic guidance and become increasingly common because of their obvious benefits to patients. The Cardiac Cath lab is generally considered an area where exposure to radiation is particularly high with compare to other departments like radiology, urology, and surgery (operating room) etc. [1]. Patient dose during cardiologic procedures is high due to lengthy procedure and the prolonged exposure time to the patient. Radiation in the Cath lab is generated using two different modes: fluoroscopy or cine angiography(cine).Fluoroscopy is used for catheter placement and involves $95 \%$ of the total X-ray operation time but only causes $40 \%$ of the total exposure to both staff and patients.[2].This is due to pulsed screening that reduces exposure dose.Cine is used to acquire diagnostic images and to generate a permanent record of the procedure and representing $60 \%$ of total radiation exposure to staff and patients although the tube operation time is very less $(5 \%)$.[2].This is primarily due to use of relatively high dose rapid sequence screening required to record onto film. Significant reductions in exposure can be realised by being aware of when cine is used and applying radiation safety measures accordingly.

The purpose of the study was to obtain and summarise the information on the type and procedures performed in the Cardiac Cath lab of the institute and to find out the local diagnostic reference levels to estimate the significance of the radiation doses for the most common procedures like -coronary angiography of trans-femoral approach (CA-TFA), 
coronary angiography of trans-radial approach (CA-TRA) and PTCA (percutaneous Transluminal coronary angioplasty with angiography).

Diagnostic reference levels (DRLs) were introduced by the International Commission on Radiological Protection [3] in 1996 and are now widely accepted as a dose management tool for X-ray examinations. The definition and implementation of DRLs are straightforward in the case of well-defined examinations, where standard protocols are used, such as in radiography and computed tomography procedures. However, establishing DRLs of Interventional Cardiology procedure is a challenging job because of wide variation of fluoroscopy time and number of images acquired during each procedure. Therefore the DRLs for a particularinvasive radiological procedure are the levels of dose, or other parameter (e.g.fluroscopy time, number of cine frames), usually defined in terms of the $75^{\text {th }}$ percentile of the distribution of the parameter in question, that are determined from the study of a large number of patients of typical weight and height who underwent the specific procedure in different diagnostic or therapeutic centres in different countries. The reasoning is that since $75 \%$ of medical centres can complete this procedure in an absolutely satisfactory way from the medical point of view, following a protocol that entails a dose below the DRL, then it is reasonable to expect the remaining $25 \%$ to modify their protocol in order to keep the patient dose below the level laid down by the DRL.There must be a DRL for every radiological examination[4].The World Health Organisation suggests that DRLs should be expressed as quantities that are easily measurable, while providinguseful information about the patient dose[5]. Since, no studies were made at the regional level to estimate the significance of the radiation doses, it is necessary to obtain the local diagnostic reference level for optimization of radiation protection.

Objective: The primary objective of the study was to evaluate the level of radiation dose received by the patients in order to estimate local diagnostic reference levels during cardiac catheterization procedures individually in terms of $\mathrm{E}$ (effective dose). Effective dose and doses to various organs estimated with the help of Monte Carlo PCXMC software. 


\section{MATERIALS AND METHODS:}

Dose quantities:

To characterise patient exposure in interventional procedures the following Dosimetric quantities were used:

Dose (Air kerma) area product (PKA)-this quantity is strictly defined as the integral of the air kerma over the area of the beam in a plane, perpendicular to the central axis of the X-ray beam $[6,7]$. With certain limitations this definition can be simplified to the product

$$
P \kappa A=K_{\text {air }}(z) A z
$$

Where $K_{\text {air }}(z)$ is the air kerma measured on the central axis of the beam at a distance $z$ from the focal spot, and $A z$ is the field area in a plane, perpendicular to the central axis of the beam at the same distance $z$ [8].As $K_{\text {air }}(z)$ decreases with the square of the distance from the focus $z$,while the field area $A z$ increases with the same factor, the product of the two remains invariant with regard to the distance from the focus of the X-ray tube. The unit of kerma area product is $\mathrm{Gym}^{2}$; its derivatives $\mu \mathrm{Gym}^{2}, \mathrm{Gycm}^{2}$ and others are also frequently used. In many references this quantity is also denoted by $K A P$ and is useful for the estimation of patient effective dose.KAP is also known as dose-area product $(D A P)$.

$P K A$ is informative of the risk of stochastic effects in patients and is the only measurable quantity in complex combined examinations that involve a series of radiographic and fluoroscopic images with a constantly changing focus-patient skin distance, exposure parameters and field size. $P K A$ also provides information about field collimation, which is a very effective way of both decreasing patient and staff dose and enhancing image quality.

$P K A$ can be measured by a KAP meter: a transmission plate-parallel ionisation chamber connected to an electrometer and mounted on the exit surface of the X-ray tube, below or over the housing.KAP meters should be calibrated by the supplier every time they are installed on an X-ray unit, following major repair or upgrade of the unit or otherwise at least once a year [9].The calibration factor derived during calibration depends strongly on exposure parameters such as field size,collimation,mode of operation, tube current and voltage, and therefore has to be determined individually for all commonly used sets of conditions. 
The uncertainty of the calibration factor derived in this manner was estimated using the principles outlined in the guide to the expression of uncertainty in measurement and in the IAEA code of practice for dosimetry in diagnostic radiology $[6,10]$.

Cumulative dose (CD)- the absorbed dose in air at the interventional reference point (IRP).For systems with an Isocentre this is a point on the reference axis, $15 \mathrm{~cm}$ from the Isocentre towards the focal spot[11].This distance is assumed to represent a good approximation of the value of the actual focus-skin distance during interventional procedures and thus with certain limitations the cumulative dose could be used as rough guidance to the risk of the occurrence of deterministic skin injuries; however,this is a good approximation only if the procedure involves just one beam projection. In actual interventional procedures where beams at many different angles are employed, the relationship between CD and the maximum skin dose (MSD) is not straightforward. Depending on the type and geometry of the procedure and the projections used, $C D$ can either underestimate or overestimate MSD.The relationship between CD and MSD should be studied for a sample of patients on each unit before CD can be used as a reliable indication for MSD [12, 13].

Entrance surface air kerma rate (ESAK rate) - The air kerma rate measured at the surface of the patient.

Entrance Skin Absorbed dose (ESD) - Once the entrance air kerma averaged over the X-ray field $\left(\mathrm{ESAK}\right.$ or $\left.\mathrm{K}_{\mathrm{e}}, \mathrm{a}\right)$ is evaluated, the entrance skin absorbed dose (ESD) can be calculated from the following equation:

$$
E S D=f(E) \times B(A, E) \times K_{e}, a
$$

In the above equation $\mathrm{f}(\mathrm{E})$ is the energy-dependent f-factor that converts air-kerma into absorbed skin dose. Since the X-ray beam is mainly bremsstrahlung, only an estimate of this factor is possible. It can be used a factor of 1.06mGy tissue absorbed dose per mGy air kerma [14]. The factor B (A, E) is the backscatter factor that considers the added dose to the skin area from radiation scattered backward from the patient's bodybackward toward the entrance skin surface. This factor depends on the area of the beam and the quality of the bremsstrahlung radiation. Only an estimate of this factor is possible, and it typically ranges from 1.2-1.4 for diagnostic X-ray beams [15]. we used a factor of 1.3 for this study. Therefore, the ESD in this study, as derived from DAP and portal film beam area is:

$$
\mathrm{ESD}=1.3 \times \mathrm{K}_{\mathrm{e}}, \mathrm{a}
$$


Effective Dose (E):To assess the radiation risk during cardiac catheterization, knowledge of the effective dose is required (ICRP 1991). This quantity is difficult to measure directly, and conversion factors must therefore be employed which relate effective dose to measurable quantities such as DAP (dose area product). In cardiac catheterization procedure various complex projections in terms of rotation of the image intensifier/X-ray tube and the gantry are involved, so Monte Carlo studies are the only practicable and acceptable approach for getting the effective dose [16].In the present work, each calculation was done with commercially available Monte Carlo simulation software PCXMC, version 2.0 rotation, which wasdeveloped by STUK, Radiation and Nuclear Safety Authority, Finland in 2012. There are software simulations available that can calculate the skin dose, organ dose and effective dose using the Monte Carlo radiation transport calculations. The Monte Carlo technique is a computational method based on the mathematical simulation of physical processes. Harrison et al [17] used the software XDOSE (NRPB,Oxon,UK) and Delichas et al [18] used the ODS-60 software (Rados Technology,Turku,Finland) to determine E from DAP measurements. Schultz and Zoetelief [19] and Bogaert et al [20] determined hospitalspecific dose conversion coefficients for DAP to E, generated by the Monte Carlo simulation code PCXMC.Compagnone [21] used theNRPB model [22] and Bozkurt model [23] to generate E from DAP.Morrell et al [24] developed a mathematical model to calculate skin dose distribution using exposure and projection data from DICOM headers of patient data.

PCXMC is a PC-based Monte Carlo program for calculating patient organ dose, effective dose and the risk of death from radiation induced cancers in medical X-ray examinations. The Monte Carlo method of photon transport calculation is based on stochastic mathematical simulation of interactions between photons and matter. Photons are emitted from a point source into the solid angle specified by the focal distance and the X-ray field dimensions, andfollowed. The photon will randomly interact with the phantom according to the probability distributions of the physical process that they may undergo: photoelectricabsorption, coherent scattering (Rayleigh) or incoherent scattering (Compton).Other interactions are not considered in PCXMC because the maximum photon energy is limited to $150 \mathrm{keV}$. At each interaction point the energy deposition to the organ at that position is calculated and stored for dose calculation. This chain of interaction events forms a so-called history of an individual photon. A large number of independent photon histories is generated and estimates of the mean values of energy depositions in the various organs of the phantom are used for calculating the doses in these organs [25]. 
The data calculated by PCXMC have been earlier compared to the organ dose conversion factors calculated in NRPB by Jones and Wall [26] and Hart et al [27] and were found to agree well [25].Reasonable agreement of PCXMC results has also been found in many comparisons with dose measurements and calculations with other phantom models, e.g., Schmidt et al [28] and Schultz et al [29].

PCXMC allows free adjustment of the X-ray beam projection (tube angulations) and other examination conditions of projection radiography and fluoroscopy. It uses anatomical data based on the mathematical hermaphrodite phantom models of Cristy and Eckerman [30], which describe patients of six different ages: new-born, 1, 5, and 10, 15 year old and adult, with some modifications to make them more realistic for external irradiation conditions and to enable the calculation of the effective dose according to the new ICRP publication 103 tissue weighting factors. The phantom weight and height is user- adjustable. All organ doses calculated by this program are relative to the incident air kerma. The air kerma is the kinetic energy released in matter at the point where the central axis of the X-ray beam enters the patient. It is given in units of milligray (mGy), free in air and without backscatter. The user must supply the amount of radiation input as either the entrance exposure $(\mathrm{mR}$, free in air, without backscatter), air kerma-area product or dose-area product (mGy.cm²),or exposurearea product $\left(\mathrm{R} \cdot \mathrm{cm}^{2}\right)[31]$.

Beam direction and exposure parameters continuously vary during all three procedures. The projections used during the above procedures were postero-anterior, right anterior oblique (RAO), left anterior oblique (LAO) and left lateral (LLAT).For each procedure, DAP measurements were recorded separately for each of the above projections. Correction factor for patient table was also considered for each projection depending on whether the patient table intercepted the beam or not.After that the DAP values were applied to the software to get various organ doses and effective doses.A dose calculation using PCXMC involves three steps-(1) defining the examination conditions, (2) performing the Monte Carlo Simulation, and (3) calculating the organ doses for a specified X-ray spectrum and patient input dose.

In defining the examination, phantom data and geometric data for the X-ray beam is required. Phantom data includes selecting an age group, phantom height and mass and whether the arms are included. Geometric data includes FSD, beam width and height (as measured at the distance FSD from the focal spot and in the plane that is normal to the central axis of the Xray beam), projection angle, cranio-caudal angle and a reference point inside the phantom (Xref, Yref, Zref). 
A phantom image and a radiograph image are available to assist with finding proper coordinates for the reference point inside the phantom, through which the central axis of the X-ray beam is directed. Figure (1) is a screenshot defining the PA examination in the PCXMC program [31].

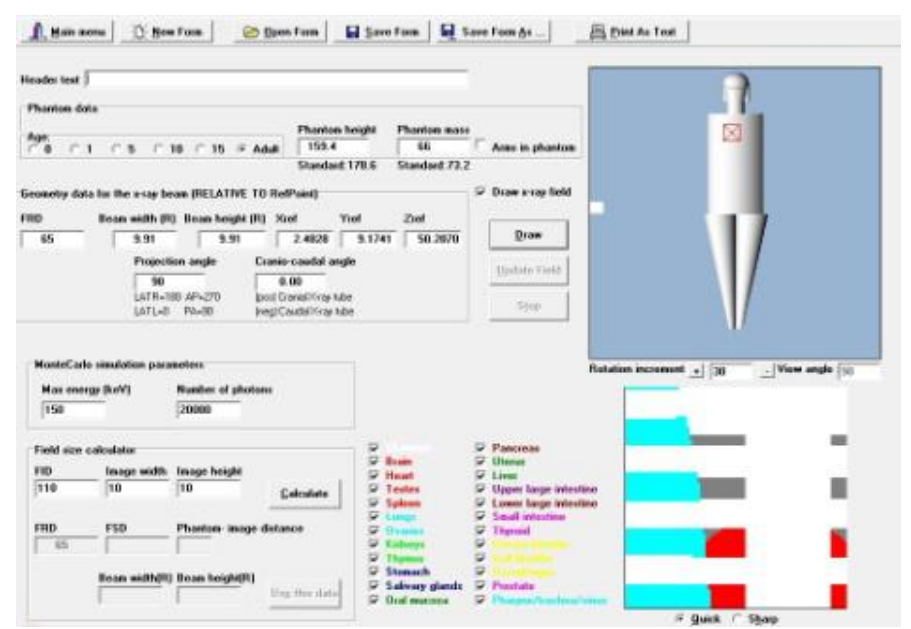

Figure 1: Screenshot of PCXMC simulation. The bottom right is a radiograph of the anatomy selected by the X-ray beam geometry.

Angiographic equipment: All procedure were performed in a single angiographic room equipped with a flat-panel detector based angiographic system (model: Allura X-per FD-10 and make: Phillips Healthcare).The Automatic Brightness Control (ABC) mode of operation is the use of a set of rules (algorithms) that control the system's response to dynamic changes in imaging conditions. Usually these control algorithms maintain the absorbed energy fluence per pixel at the imaging detector's X-ray capture layer, resulting in a reasonably constant average signal level from the detector for a given detector field of view (FOV). The absorbed energy fluence is maintained by controlling the exposure parameters of the X-ray generator such that a constant, pre-defined detector signal level is achieved. These parameters are $\mathrm{kV}$, $\mathrm{mA}$, pulse width and filtration. In pulsed fluoroscopy, the exposure is pulsed rather than continuous and the pulse width is the exposure time of each pulse in milliseconds. One of the five methods commonly employed are:(1) a change in $\mathrm{kVp}$ with a fixed $\mathrm{mA},(2)$ a change in $\mathrm{mA}$ with fixed $\mathrm{kVp}$, (3) a change in the $\mathrm{kVp}$ and the $\mathrm{mA}$ simultaneously (4) a change in pulsed width adjunct to the three methods mentioned and (5) a change in filtration. Usually a central area on the imager receptor is utilised to sample the signal intensity as the input signal for the $\mathrm{ABC}$ [32].The number of frames is routinely set at 15 frames per second for both fluoroscopy and cine acquisition procedures. In this study the patient skin dose and DAP were determined using a transmission chamber fitted to an X-ray tube light beam diaphragm. 
Quality assurance measurements were periodically performed throughout the course of the study to ensure proper functioning of the equipment.

\section{RESULTS:}

Settings: We designed a retrospective, single-centre analysis of patient radiation exposure during both diagnostic and therapeutic interventional coronary procedures performed at our institute. Our hospital is an academic centre with a catheterization laboratory performing more than ten years. Our study was approved by the institutional ethical committee on human research.

Study Population: To assess the predictors of increased radiation exposure, we included all common procedures (coronary angiography (CA) and percutaneous Transluminal coronary angioplasty (PTCA) with stent placement) in thestudy. Clinical and procedural data were retrieved from an electronic database in which all procedures are prospectively recorded. The following data were collected retrospectively in a designed format during both diagnostic (Coronary angiography) and therapeutic procedure (Percutaneous Transluminal Coronary Angioplasty). Patient demographic data like age, height, weight and BMI (body mass index) are presented in

Table-I.

Table I: The mean values and (the range) for patient bio-data.

\begin{tabular}{|c|c|c|c|c|c|}
\hline Group & No & $\begin{array}{c}\text { Age } \\
\text { (years) }\end{array}$ & $\begin{array}{l}\text { Height } \\
(\mathrm{cm})\end{array}$ & $\begin{array}{l}\text { Weight } \\
(\mathrm{kg})\end{array}$ & $\begin{array}{c}\text { Body mass Index } \\
\qquad\left(\mathrm{kg} / \mathrm{m}^{2}\right)\end{array}$ \\
\hline All & 123 & $\begin{array}{c}58.14 \\
(30-85)\end{array}$ & $\begin{array}{c}158.94 \\
(148-174)\end{array}$ & $\begin{array}{c}66.57 \\
(52-80)\end{array}$ & $\begin{array}{c}26.25 \\
(21.37-34.47)\end{array}$ \\
\hline $\begin{array}{c}\text { Coronary } \\
\text { angiography } \\
\text { (TFA) }\end{array}$ & 87 & $\begin{array}{c}58.51 \\
(30-85)\end{array}$ & $\begin{array}{c}159.41 \\
(149-174)\end{array}$ & $\begin{array}{c}65.58 \\
(52-78)\end{array}$ & $\begin{array}{c}25.80 \\
(21.4-31.2)\end{array}$ \\
\hline $\begin{array}{l}\text { Coronary } \\
\text { angiography } \\
\text { (TRA) }\end{array}$ & 10 & $\begin{array}{c}53.7 \\
(36-69)\end{array}$ & $\begin{array}{c}157.9 \\
(148-164)\end{array}$ & $\begin{array}{c}67.5 \\
(60-78)\end{array}$ & $\begin{array}{c}27.08 \\
(25.1-29.4)\end{array}$ \\
\hline $\begin{array}{l}\text { Coronary } \\
\text { angiography } \\
\text { (PTCA) }\end{array}$ & 26 & $\begin{array}{c}58.58 \\
(40-82)\end{array}$ & $\begin{array}{c}157.77 \\
(154-162)\end{array}$ & $\begin{array}{c}69.5 \\
(58-80)\end{array}$ & $\begin{array}{c}27.93 \\
(23.7-32.5)\end{array}$ \\
\hline
\end{tabular}

Exposure factors: DAP (Dose area product), exposure time (both Fluro and total including cine), ESD (Entrance Surface Dose) andE (Effective dose) are presented in Table-II. 
Table II: Summary of patient radiation data for CATH-Lab.

\begin{tabular}{|c|c|c|c|c|c|c|c|}
\hline Study & $\begin{array}{l}\text { Sample } \\
\text { (No) }\end{array}$ & $\begin{array}{c}\text { DAP } \\
\left(\mathrm{Gy} \mathrm{cm}^{2}\right)\end{array}$ & $\begin{array}{l}\text { Total time } \\
\text { (Fluro) } \\
\text { (minute) }\end{array}$ & $\begin{array}{c}\text { Cine } \\
\text { frame } \\
\text { (images) }\end{array}$ & $\begin{array}{c}\text { Air Kerma } \\
\text { (cumulative) } \\
\text { (Gy) }\end{array}$ & $\begin{array}{c}\text { Entrance } \\
\text { Surface Dose } \\
\text { (ESD) } \\
\text { (Gy) }\end{array}$ & $\begin{array}{l}\text { Effective } \\
\text { Dose } \\
(\mathrm{mSv})\end{array}$ \\
\hline CA-TFA & 87 & $\begin{array}{c}32.43 \\
(11.85-91.74)\end{array}$ & $\begin{array}{c}3.00 \\
(1-23.0)\end{array}$ & $\begin{array}{l}345 \\
(140- \\
1787)\end{array}$ & $\begin{array}{c}0.31 \\
(0.12-0.93)\end{array}$ & $\begin{array}{c}0.44 \\
(0.162-1.30)\end{array}$ & $\begin{array}{c}6.13 \\
(2.4-17.33)\end{array}$ \\
\hline $\begin{array}{l}\text { CA- } \\
\text { TRA }\end{array}$ & 10 & $\begin{array}{c}57.16 \\
(28.95-151.2)\end{array}$ & $\begin{array}{c}5.5 \\
(3.0-15)\end{array}$ & $\begin{array}{c}382 \\
(316-988)\end{array}$ & $\begin{array}{c}0.52 \\
(0.33-1.53)\end{array}$ & $\begin{array}{c}0.83 \\
(0.47-2.14)\end{array}$ & $\begin{array}{l}10.97 \\
(5.56- \\
29.03)\end{array}$ \\
\hline $\begin{array}{l}\text { CA- } \\
\text { PTCA }\end{array}$ & 26 & $\begin{array}{c}157.64 \\
(48.35-319.1)\end{array}$ & $\begin{array}{c}18.50 \\
(7.0-37)\end{array}$ & $\begin{array}{l}1208 \\
(705- \\
2492)\end{array}$ & $\begin{array}{c}1.87 \\
(0.67-3.77)\end{array}$ & $\begin{array}{c}2.61 \\
(0.93-5.27)\end{array}$ & $\begin{array}{c}34.68 \\
(10.64- \\
70.21)\end{array}$ \\
\hline
\end{tabular}

The estimated patient dose rate as a whole in the Cath-Lab was found to be $96.45 \mathrm{mGy} / \mathrm{min}$ which is considered lower than the recommended DRL(dose reference level) for the continuous high mode fluoroscopy used in interventional radiology $(100 \mathrm{mGy} / \mathrm{min})$ given by IAEA.The mean estimated value of DAP were 32.43(range 11.85-91.74),57.16(range 28.95151.2)and 157.64(48.35-319.1) $\mathrm{Gycm}^{2}$ for CA-TFA(coronary angiography with transfemoral approach),CA-TRA(coronary angiography with trans-radial approach)and PTCA(percutaneous Transluminal coronary angioplasty with angiography) respectively.The estimated value of ESD for all three procedures were 0.44Gy (range 0.162-1.30), 0.83Gy (range 0.47-2.14) and 2.61 Gy (range 0.93-5.27).

The mean effective dose to patient in CA-TFA was $6.13 \mathrm{mSv}$, where maximum and minimum values were 17.33 and $2.4 \mathrm{mSv}$ respectively. It is also found that median, $1 \mathrm{st}$ and $3^{\text {rd }}$ quartile values for this procedure were5.78, 4.68 and $8.38 \mathrm{mSv}$ respectively. For CA-TRA the mean effective dose was $10.97 \mathrm{mSv}$, where maximum and minimum values were 29.03 and $5.56 \mathrm{mSv}$ respectively. The median, $1 \mathrm{st}$ and $3^{\text {rd }}$ quartile values for CA-TRA were 9.41, 6.89 and $15.98 \mathrm{mSv}$ respectively. And for CA-PTCA the mean effective dose was $34.68 \mathrm{mSv}$, where maximum and minimum values were 70.21 and $10.64 \mathrm{mSv}$ respectively. The median, 1 st and $3^{\text {rd }}$ quartile values for CA-PTCA were $31.82,22.88$ and $47.96 \mathrm{mSv}$ respectively Table-IIIpresents the mean doses to few of the most irradiated organs (lungs, Oesophagus, thyroid, Liver, bone marrow, Heart and Stomach) and mean effective dose with the values of standard deviation. 
Table-III: Mean organ doses (mGy) and mean effective dose (mSv).

\begin{tabular}{|c|c|c|c|c|c|c|c|c|}
\hline \multirow{2}{*}{$\begin{array}{l}\text { Procedu } \\
\text { re }\end{array}$} & \multicolumn{7}{|c|}{ Organ Dose (mGy) } & \multirow{2}{*}{$\begin{array}{c}\text { Effective } \\
\text { dose } \\
(\mathrm{mSv})\end{array}$} \\
\hline & Lungs & $\begin{array}{c}\text { Oesophag } \\
\text { us }\end{array}$ & Thyroid & Liver & $\begin{array}{c}\text { Bone } \\
\text { Marrow }\end{array}$ & Heart & Stomach & \\
\hline $\begin{array}{l}\text { CA- } \\
\text { TFA }\end{array}$ & $\begin{array}{c}20.77 \pm 1 \\
06\end{array}$ & $\begin{array}{c}36.24 \pm 2.4 \\
8\end{array}$ & $\begin{array}{c}1.91 \pm 2 . \\
40\end{array}$ & $\begin{array}{c}2.04 \pm 1 . \\
06\end{array}$ & $\begin{array}{c}18.89 \pm 3 \\
02\end{array}$ & $\begin{array}{c}28.07 \pm 1 \\
59\end{array}$ & $\begin{array}{c}1.84 \pm 2 . \\
26\end{array}$ & $6.13 \pm 3.08$ \\
\hline $\begin{array}{l}\text { CA- } \\
\text { TRA }\end{array}$ & $\begin{array}{c}35.29 \pm 1 \\
11\end{array}$ & $\begin{array}{c}54.98 \pm 2.5 \\
0\end{array}$ & $\begin{array}{c}1.99 \pm 2 . \\
48\end{array}$ & $\begin{array}{c}6.31 \pm 1 . \\
08\end{array}$ & $\begin{array}{c}28.71 \pm 3 \\
05\end{array}$ & $\begin{array}{c}54.03 \pm 1 \\
62\end{array}$ & $\begin{array}{c}4.12 \pm 2 . \\
31\end{array}$ & $\begin{array}{c}10.97 \pm 7.1 \\
0\end{array}$ \\
\hline $\begin{array}{l}\text { CA- } \\
\text { PTCA }\end{array}$ & $\begin{array}{c}74.41 \pm 1 \\
80\end{array}$ & $113 \pm 2.80$ & $\begin{array}{c}6.37 \pm 2 . \\
76\end{array}$ & $\begin{array}{c}6.73 \pm 2 . \\
01\end{array}$ & $\begin{array}{c}59.28 \pm 3 \\
09\end{array}$ & $\begin{array}{c}87.92 \pm 1 \\
53\end{array}$ & $\begin{array}{c}5.95 \pm 2 . \\
75\end{array}$ & $\begin{array}{c}34.68 \pm 16 \\
85\end{array}$ \\
\hline
\end{tabular}

Statistical analysis: For analysis of data, continuous variables were checked for normal distribution using K-S test (Kolmogorov-Smirnov). Normally distributed data and nonparametric data were compared using the Student's t-test and Mann-Whitney U test respectively. Correlations between continuous variables were obtained by the Pearson correlation coefficient or the Spearman correlation coefficient if variables were not normally distributed. A P-value $<0.05$ was considered as statistically significant.

\section{DISCUSSION:}

A total of 123 consecutive cardiac intervention procedures were studied. Out of that 78.86 \%of the performed procedures were coronary angiography (CA) and $21.14 \%$ were percutaneous Transluminal coronary angioplasty (PTCA).

The cardiac catheterization lab is a department specializing in the diagnosis and treatment to a range of heart conditions without open heart surgery. For most angiography the first 4-5 minutes is the diagnostic part known as the standard coronary angiogram (CA) to evaluate or confirm the presence of coronary artery disease, valve disease, and heart muscle function.If no blockage is found, no further investigationis required. In cases where an issue is found, special types of interventions like PTCA and balloon angioplasty with stent placement etc.may be performed to open the artery. In our centre a majority of cardiac catheterizations (90\%) are carried out with arterial access achieved via femoral artery, however the number of catheterizations utilizing trans-radial access $(10 \%)$ is become popular among the cardiologist 
as this approach has been shown to reduce complication rates and reduce hospital stay [33].Despite this advancements, adoption of trans-radial catheterization demonstrated with a significant increase $(\mathrm{P}<0.05)$ ofradiation exposure to the patients. This was probably related to the more complicated catheter manipulation requiring a prolonged fluoroscopic time. A further study for the radial approach is required to compare the dose involvement of patients in both right and left trans-radial access.

Effective dose values found for our study are reasonable compared to those found in other studies in the world which lies in the range from 3 to $22 \mathrm{mSv}$ in coronary angiographic (CATFA, CA-TRA) procedure, from 5.4 to $41.0 \mathrm{mSv}$ for coronary angioplasty with angiography procedure (CA-PTCA)(Table-IV).In case of CA-PTCA, the effective dose is found to be high since both angiography and angioplasty procedure contribute the total effective dose to the patient.

Table IV: Studies reporting mean effective dose of coronary angiography and coronary angioplasty procedures.

\begin{tabular}{|c|c|c|c|c|c|}
\hline \multirow{2}{*}{ Previous studies } & \multirow{2}{*}{ Year } & \multirow{2}{*}{ Group } & \multicolumn{3}{|c|}{ Mean effective dose (mSv) } \\
\hline & & & $\mathrm{CA}$ & PTCA & $\mathrm{CA}+\mathrm{PTCA}$ \\
\hline Karppinen et al. & 1995 & $\ldots$. & $\ldots$. & $\ldots$. & 10.6 \\
\hline Leung and Martin & 1996 & $\ldots$. & 3.1 & .... & .... \\
\hline \multirow{2}{*}{ Broadhead et al. } & \multirow{2}{*}{1997} & Room A & 9.4 & 14.2 & ... \\
\hline & & Room B & 4.6 & 10.2 & $\ldots$ \\
\hline Betsou et al. & 1998 & $\ldots$ & 5.6 & 6.9 & 9.3 \\
\hline Harrison et al. & 1998 & $\ldots$ & 3.4 & $\ldots$ & $\ldots$ \\
\hline Neofotistou et al. & 1998 & $\ldots$. & $4.6-15.8$ & $\ldots$ & $5.4-41.0$ \\
\hline Katritsis et al. & 2000 & $\ldots$ & 5.0 & 6.6 & 13.6 \\
\hline Lobotessi et al & 2001 & $\ldots$. & 13.2 & $\ldots$ & $\ldots$ \\
\hline Delichas et al. & 2003 & $\begin{array}{l}\text { Hospital A } \\
\text { Hospital B }\end{array}$ & $\begin{array}{l}22.7 \\
17.9\end{array}$ & $\begin{array}{l}30.5 \\
14.7\end{array}$ & $\cdots$ \\
\hline
\end{tabular}




\begin{tabular}{|c|c|c|c|c|c|}
\hline Efstathopoulos et al. & 2003 & $\ldots$ & 5.0 & $\ldots$. & 14.8 \\
\hline Hunold et al. & 2003 & $\ldots$ & 2.3 & $\ldots$ & $\ldots$ \\
\hline Sandborg et al. & 2004 & $\begin{array}{c}\text { Femoral } \\
\text { Radial }\end{array}$ & $\begin{array}{l}6.8 \\
9.2\end{array}$ & $\cdots$ & $\begin{array}{c}8.6 \\
13.5\end{array}$ \\
\hline ViktorieStisova & 2004 & $\begin{array}{l}\text { Workplace A1 } \\
\text { Workplace A2 } \\
\text { Workplace B } \\
\text { Workplace C }\end{array}$ & $\begin{array}{l}8.8 \\
3.6 \\
7.9 \\
2.7\end{array}$ & $\begin{array}{l}\cdots . \\
\cdots . \\
\cdots \\
\cdots\end{array}$ & $\begin{array}{c}\ldots . \\
9.7 \\
15.3 \\
5.7\end{array}$ \\
\hline Vijayalakshmi et al & 2007 & $\ldots$ & 4.4 & $\ldots$ & $\ldots$ \\
\hline MMM Siraz et al. & 2014 & $\ldots$ & 3.30 & 24.14 & 25.56 \\
\hline Tsapaki V et al. & 2017 & $\ldots$ & 6.57 & 21.6 & $\ldots$ \\
\hline Our study & 2019 & $\begin{array}{c}\text { Femoral } \\
\text { Radial }\end{array}$ & $\begin{array}{c}6.13 \\
10.97\end{array}$ & & 34.68 \\
\hline
\end{tabular}

DAP to effective dose conversion coefficients estimated for CA-TFA $(0.189 \mathrm{mSv} / \mathrm{Gy}$ $\left.\mathrm{cm}^{2}\right)$,CA-TRA $\left(0.192 \mathrm{mSv} / \mathrm{Gycm}^{2}\right)$ and PTCA $\left(0.22 \mathrm{mSv} / \mathrm{Gycm}^{2}\right)$ are comparable to those reported for other interventional radiology examinations.NRPB estimated the coefficients for barium meal and barium enema to be 0.22 and 0.28 respectively [22].Leung and Martin [34]using Monte Carlo tabulated values estimated a conversion factor of 0.22 for CA procedure. Using the same approach,Broadhead et al.[35]estimated conversion factors in the range 0.183-0.206 for CA and PTCA.The lower values compared to those derived in this study can be attributed to the use of the MC method, which as pointed out by Rannikko et al.[36], underestimateseffective dose compared to the ODS-60 calculation method which takes into account the patient's sex and size.Betsou et al [37]using TLD measurements in a Rando-phantom,estimated the conversion factor to be 0.183 for interventional cardiology procedures.

Figure 2 shows the strong correlation between total duration of procedure (both fluoroscopy and cine time) witheffective dose $(\mathrm{R}=0.95, \mathrm{p}<0.00001)$ and Figure 3 shows weak although statistically significant correlation between BMI (body mass index) and effective $\operatorname{dose}(\mathrm{R}=0.525, \mathrm{p}<0.00001)$. A significant increase of doses in TRA procedure regarding TFA procedure was also noticed in our study. 


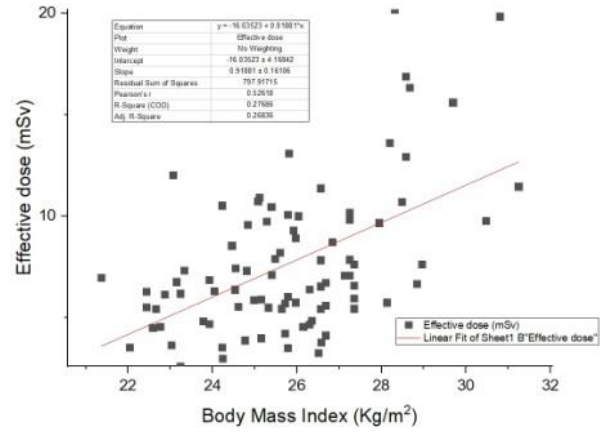

Figure 2:BMI vs. E

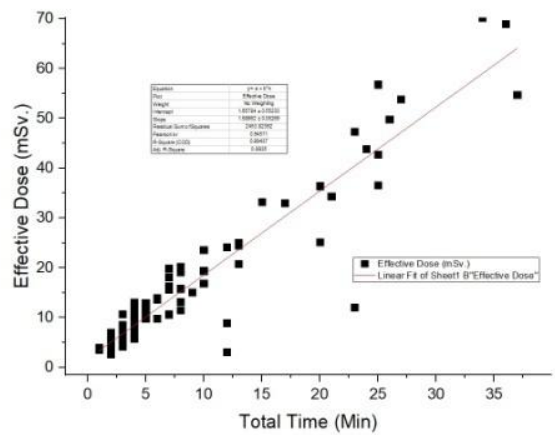

Figure 3: T (total time in min) vs.E

The cardiologist who is working in the cath-lab may reduce the radiation exposure by following good work practices such as: a reduction of beam- on time, an increase in distance from the irradiating patient, and the use of shielding between patient and physician. The beam-on time may be reduced by avoiding pointless cine recording; by pausing the fluoroscopy and "freezing" the image; by using pulsed fluoroscopy or cine recording with a low pulse rate; by keeping in mind the five- and ten-minute warning sounds provided by the angiographic machine; and by adequate preparation before the examination. The drop in the radiation exposure may be achieved by increasing the distance from the patient. During oblique and lateral projections the physician should avoid being on the side of the tube, since the dose rate can be reduced by as much as by standing on the side of the receptor. If the image quality is optimum, the patient's exposure may be reduced by avoiding using any magnified field size of projected beam.

Study Limitations: Our study presents several limitations, including the observational, retrospective design. Moreover; we did not measure the exposure of working staff, which is an important parameter for radiation protection optimization.

\section{CONCLUSIONS}

Patient and staff dose reduction is of a prime importance and practitioners should optimize the radiation dose by applying proper technique without compromising the diagnostic and therapeutic findings. We have noticed a wide range of effective dose values due to the case complexity factor, which could not take into account in our studies. It is common for patients to have multiple coronary angiography procedures, thus increasing their potential lifetime radiation dose which may lead to an increase in their lifetime attribute risk from radiation. It is anticipated that this study is going to assist the institutions having Cath-Lab facilities of 
this region in encouraging the standardisation of procedure, which may help increase awareness and aims to serve as guidance for Cardiologist.

\section{References:}

[1] International Commission on Radiological Protection. Radiological Protection and safety in Medicine; ICRP- 73, Pergamum Press ;1997

[2] E.T.Samara,A.Aroua,R.D.Palma,J.C.Stauffer,S.Schmidt,Ph.R.Trueb,A.Stuessi,R.Treier, E.Bochud, F.R.Verdun.An audit of Diagnostic reference levels in Interventional Cardiology and Radiology: are there differences between academic and non-academic centres? Radiation Protection Dosimetry 2011; 1-9.

[3] International Atomic Energy Agency .Dosimetry in diagnostic radiology: an international code of practice. Technical Reports Series No.457.IAEA, Vienna;2007

[4] Stratis A.I.,Anthopoulos P.L.,Gavaliatsis I.P.,Ifantis G.P.,Salahas A.I.et .al.;Patient dose in Cardiac Radiology;Hellenic J Cardiology 2009;50:17-25.

[5] Shrimpton P,SharpC,NeofotistouV,etal.Efficacy and radiation safety in interventional radiology.Joint WHO/Institute of Radiation Hygiene Radiology,Report by working Group 2 on Radiation safety,Munich-Neuherberg:1995.

[6] International Electrochemical Commission. Medical electrical equipment-dose area product meters, 2nd edition, 2000-01. Publication'60580, IEC, Geneva.

[7] National Radiation Protection Board. National protocol for patient dose measurements in diagnostic radiology. NRPB, Chilton; 1992.

[8] International Organisation for Standardisation (1995) Guide to the expression of uncertainty in measurement, ISO, Geneva. International Electrochemical Commission (2008) Medical electrical equipment. General requirements for radiation protection in diagnostic X-ray equipment, Publication 60601-1-3.IEC, Englewood.

[9] TriamiA.Gasparini D. Padovani R . Trigger levels to prevent tissue reaction in interventional radiology procedures. IFMBE Proceedings 2009; 25:410-413.

[10] ŹontarD,KuheljD,ŚkrkD.Zdešar U , Patient peak skin doses from cardiac interventional procedures.RadiatProt Dosimetry 2010; 139:262-265.https://doi.org/10.1093/rpd/ncq013.

[11] Dreler.G.,Panzer W.,WidenmannL.,Williams G.,ZankiM.,The calculation of dose from external photon exposures using reference human phantoms and Monte Carlo 
methods,part-III:Organ dose in X-ray diagnosis(revised and amended),Rep.GSF-Bericht 11/90,GSF National Research Centre for Environment and Health,Neuherberg ;1990.

[12] International Atomic Energy Agency,Dosimetry in Diagnostic Radiology:An international code of practice,AppendixVIII,Technical Reports Series,2007; No.457,IAEA,Vienna.

[13] P.W.E.Schmidt,D.R.Dance,C.L.Skinner,I.A.Castellano Smith and J.G.McNeil,Conversion factors for the estimation of effective dose in paediatric cardiac angiography,Phy.Med.Biol.2000;45:3095-107.

[14] S.S.Jolly,S.Amlani,M.Hamon,S.Yusuf,andS.R.Mehta, Radial versus femoral access for coronary angiography or intervention and the impact on major bleeding and ischemic events: a systematic review and meta-analysis of randomized trials, American Heart Journal,2009;157-1:132-40.

[15] A.G.Ziakas, K.C.Koskinas, S.Gavrilidis et.al, Radial versus femoral access for orally anti coagulated patients, Catheterization and Cardiovascular Interventions, 2010;76-4:493-99.

[16] Y.J.Yang,D.E.Kandzari,Z.Gao et.al.,Transradial versus transfemoral method of percutaneous coronary revascularization for unprotected left main coronary artery disease: comparison of procedural and late-term outcomes,JACC,2010;3-10:1035-42.

[17] Harrison D,RicciardelloM,CollinsL.Evaluation of radiation dose and risk to the patient from coronary angiography.Aust NZ J Med 1998;28(5):597-603

[18] Delichas

M.G.,PsarrakosK,Molyvda A.E.,GiannogluotG,HatziioannouK,PapanastassiouE.Radiation Doses to patients undergoing coronary angiography and percutaneous Transluminal coronary angioplasty.Radiation Protection Dosimetry 2003;103(2):149-54.

[19] Schultz FW,ZoeteliefJ.Dose conversion coefficients for interventional procedures.Radiation Protection Dosimetry 2005;117 (1-3):225-30.

[20] Bogaert E,BacherK,ThierensH.Interventional cardiovascular procedures in Belgium:Effective dose and conversion factors.Radiation Protection Dosimetry 2008;129 (1-3):77-82.

[21] CompagnoneG,OrtolaniP,DomenichelliS,OviV,CalifanoG,DallAraG,etal.Effective and equivalent organ doses in patients undergoing coronary angiography and percutaneous coronary interventions.Medical Physics 2011;38(4):2168-75.

[22] Hart D,JonesDG,WallBF.Estimation of effective dose in diagnostic radiology from entrance surface dose and dose area product measurements (NRPB R262).Chilton:National Radiological Protection Board;1994. 
[23] Bozkurt A,BorD.Simultaneous determination of equivalent dose to organs and tissues of the patient and of the physician in interventional radiology using the Monte Carlo method.Physics in Medicine Biology 2007;52(2):317-30.

[24] Morrel RE,Rogers AT.A mathematical model for patient skin dose assessment in cardiac catheterisation procedures.British Journal of Radiology 2006;79 (945):756-61.

[25] Tapiovaara M,Siiskonen T.PCXMC-A Monte Carlo program for calculating patient doses in medical x-ray examinations.Helsinki:Finnish centre for Radiation and Nuclear Safety (STUK);2008.

[26] Jones DG,WallBF.Organ doses from medical x-ray examinations calculated using Monte Carlo techniques,NRPB-R186.London:HMSO;1985.

[27] Hart D, Jones DG,WallBF.Normalised organ doses for medical x-ray examinations calculated using Monte Carlotechniques,NRPB-SR262.Chilton:NRPB;1994.

[28] Schmidt P, Dance D, Skinner C, Castellano Smith I, McNeill K J. Conversion factors for the estimation of effective dose in paediatric cardiac angiography. Phys Med Biol 2000; 45 (10): 3095-107.

[29] Schultz FW, Geleijns J, Spoelstra F, Zoetelief J. Monte Carlo calculations for assessment of radiation dose to patients with congenital heart defects and to staff during cardiac catheterizations. Br J Radiol 2003; 76(909): 638-47.

[30] Eckerman K, Cristy M, Ryman J. Description of the mathematical phantoms. The ORNL mathematical phantom series; 1996

[31] Tapiovaara M, Siiskonen T. PCXMC 2.0 User's Guide. Helsinki: Finnish Centre for Radiation and Nuclear Safety (STUK); 2008.

[32] AAPM.Functionality and Operation of Fluoroscopic Automatic Brightness Control/Automatic Dose rate control Logic in Modern Cardiovascular and interventional Angiography systems.American Association of Physicists in Medicine;2012.

[33] K.Nadarasa, M.C.Robertson, C.K.Wong et.al, Rapid cycle change to predominantly radial access coronary angiography and percutaneous coronary intervention: intervention effect on vascular access site complications, Catheterization and Cardiovascular Interventions, 2012; 79-4:589-94.

[34] Leung.K.C. and Martin.C.J.Effective doses for coronary angiography.Br.J.Radiology.1996;69:426-31.

[35] Broadhead.D.A.,Chapple.C.L.,FaulknerK.,Davies M.L., and McCallum.H.The impact of cardiology on the collective effective dose in the north of England.Br.J.Radiology.1997;70:492-97. 
[36] Rannikko S.,Ermakov,I.,Lampinen J.S.,Toivonen M.,KarilaK.T.K.andChervjakov.A computing patient doses of X-ray examinations using a patient size and sex adaptable phantom.Br.J.Radiology.1997;70:708-18 .

[37] Betsou,S.,Efstathopoulos,E.P.,Katritsis,D.,Faulkner,K.,andPanayiotakis,G. Patient radiation dosesduring cardiac catheterization procedures.Br.J.Radiology.1998;71:634-39. 